\title{
Carotenoids: Potent to Prevent Diseases Review
}

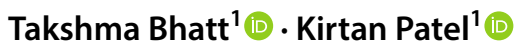

Received: 3 April 2020 / Accepted: 8 May 2020 / Published online: 13 May 2020

(c) The Author(s) 2020

\begin{abstract}
Carotenoids are the phytochemicals known for their biological activities. They are found in nature in the form of plants, algae, fungi and in microorganisms. This is the major group having two different structure one with oxygen and without oxygen. The Present article aims to present these molecules as a new therapeutic agent, as it has unrealized efficiency to prevent and reduce the symptoms of many diseases like cancer, neurodegenerative diseases such as Alzheimer, cerebral ischemia, diabetes associated with obesity and hypertension, ophthalmic diseases and many more. It can be utilized in the form of dietary supplement as nutraceutical and pharmaceutical compounds. Yet more research and developing test knowledge is needed to make it available to the humans. In this article its sources, biosynthesis, properties, applicability and commercialization of pigments from naturally produced sources are discussed.
\end{abstract}

Takshma Bhatt

Bhatttakshma@gmail.com

Kirtan Patel

Kdp612220@gmail.com

1 Department of Biotechnology, President Science

College (Affiliated to Gujarat University), Ghatlodia,

Ahmedabad 380061, India 


\section{Graphic Abstract}

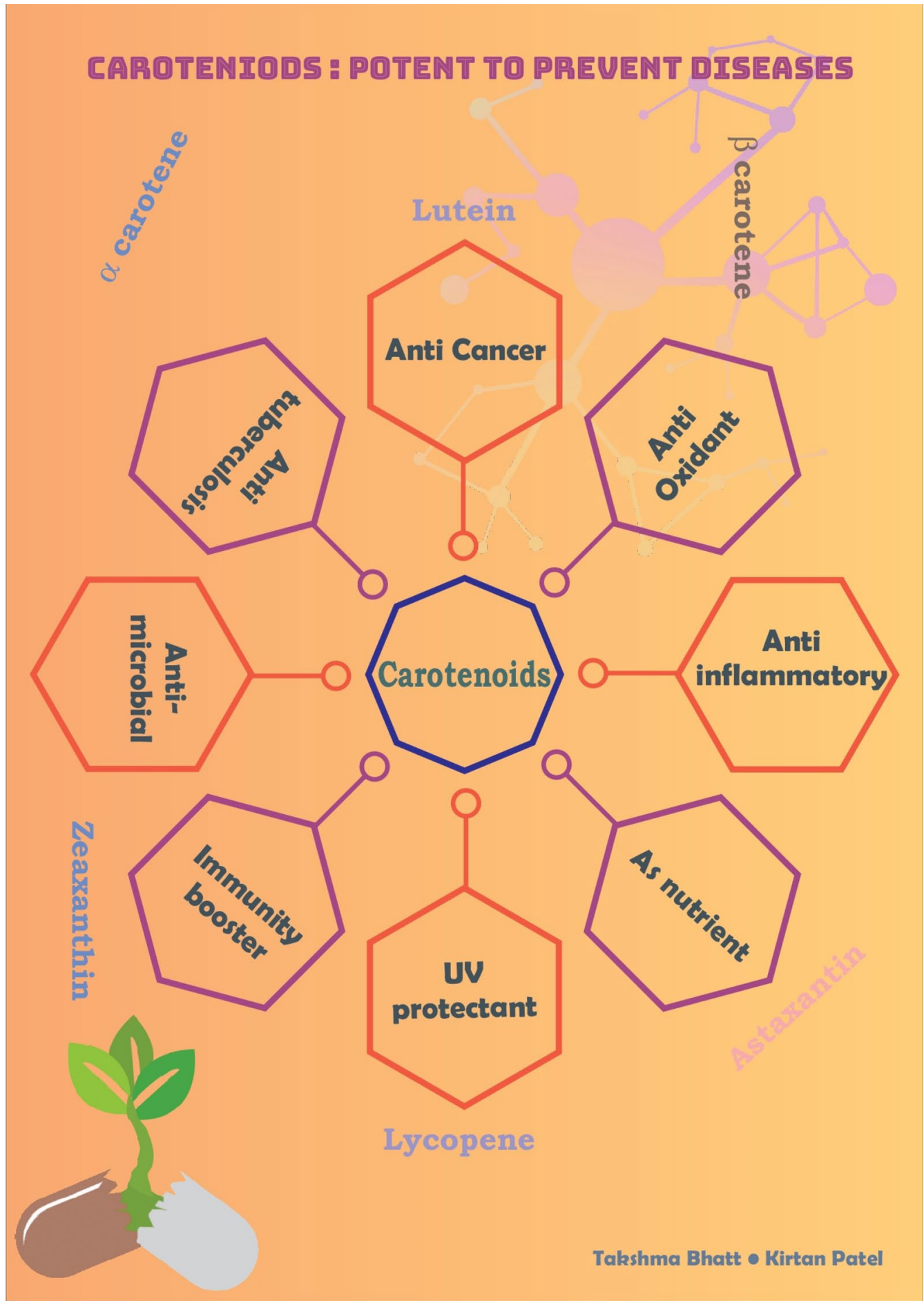

\section{Abbreviations}

CDK4 and CDK 6 Cyclin dependent kinase 4 and 6

ALS

CVD

decreasing HDL

D. salina
Amyotrophic lateral sclerosis

Cardiovascular diseases

Decreases high density lipoprotein

Dunaliella salina
GADD45 $\alpha$

GR, GPx

GSK-3 $\beta / \mathrm{AKt}$

$\mathrm{HO}-1$
Growth arrest and DNA-damageinducible, alpha Glutathione reductase and glutathione peroxidase Glycogen synthase kinase- $3 \beta$ Heme oxygenase 1 


\begin{tabular}{|c|c|}
\hline HSV-1 & Herpes simplex virus type 1 \\
\hline H. pluvialis & Haematococcus pluvialis \\
\hline IL-6 & Interleukin 6 \\
\hline $\mathrm{MBC}$ & Minimum bactericidal concentration \\
\hline MDR & Multi drug resistant \\
\hline $\mathrm{MIC}$ & $\begin{array}{l}\text { Minimum (or minimal) inhibitory } \\
\text { concentration }\end{array}$ \\
\hline M. roseus & Micrococcus roseus \\
\hline M. luteus & Micrococcus luteus \\
\hline $\mathrm{NF}-\kappa \mathrm{B}$ & $\begin{array}{l}\text { Nuclear factor kappa-light-chain- } \\
\text { enhancer of activated B cells }\end{array}$ \\
\hline $\mathrm{NO}$ & Nitric oxide \\
\hline Nrf2 & $\begin{array}{l}\text { Nuclear factor erythroid } 2 \text { related fac- } \\
\text { tor } 2\end{array}$ \\
\hline oxidizing LDL & Oxidized low-density lipoprotein \\
\hline ROS & Receptive oxygen species \\
\hline TNF- $\alpha$ & Tumor necrosis factor alpha \\
\hline UV light & Ultra violet light \\
\hline
\end{tabular}

\section{Introduction}

Carotenoids are fat-soluble, highly unsaturated red, orange, or yellow pigments that are naturally present in plants, fungi, bacteria, and algae, where intensity of colour is generally related with the number of carotenoids. Carotenoids are naturally found in abundance in vegetables and fruits. Moreover, certain photosynthetic bacteria and algae are also the good source of these compounds [1]. The phytochemical carotenoids belong to the isoprenoids and their basic structure is made up of eight isoprene units, having C 40 backbone. Majorly, two types of carotenoids can be discerned: Carotenes-the pure hydrocarbons while xanthophylls are derivatives that contain one or more oxygen functions [2]. Carotenoids collaborate with other biomolecules such as proteins and lipids to enhance its activity as anti-oxidant [3]. A noticeable function of this phytochemicals in plants are to protect the cells from extra UV light mainly not useful for photosynthesis as it induces stress on the plant cells hence, here they show their antioxidant property.Moreover, these carotenoids gets cleave into apocarotenoids which is responsible for aroma, colour and phytohormone production. It also helps in producing signals among the plant cells [4] (Fig. 1).

\section{Classification and Biosynthesis}

Carotenoids are classified into two groups: (i) the compound having single long carbon chain known as carotenes (ii) the compound having oxygen atom in its structure is known as xanthophylls. These carotenoids are further divided into the category of having provitamin A activity that is they are able to characterize further into vitamin A. Due to the lipophilic and hydrophobic nature they can be easily extracted from natural sources like green vegetables, flowers, fruits and from microorganisms. Methods used to extract carotenoids are: Supercritical fluid extraction, Solvent extraction and many other [5].

Biosynthesis of carotenoids have been studied on various vascular plants and on microorganisms from which the pathways of its occurrence came to existence known as carotenogenesis.Carotenogenesis is of five stages (i) the active isoprene are formed through isoprenoids building blocks (ii) condensation of isoprene units resulting in forming phytoene (iii) formation of lycopene through extension by four desaturation steps and isomerization (iv) cyclization of lycopene ends to form carotenes (v) involvement of oxygen to form various xanthophylls [1, 2] (Fig. 2).

\section{Properties}

\subsection{Anti-oxidation}

Mainly diseases are caused due to free moving oxygen radicles in the body. Diseases like cancer, cardiovascular diseases, ophthalmic diseases, neurodegenerative diseases are caused due to free radicles [6]. Carotenoids are able to scavenge the free oxygen radicals from the body which helps in curing certain types of cancer and reduce the formation tumour in cancer patients. Moreover, certain carotenoids are found to activate the antioxidant gene expression through Nrf2 (Nuclear factor erythroid 2 related factor 2) transcriptional factor which helps in decreasing neurological disorder and diabetes [7, 8]. Another study has reported that carotenoids extracted from $M$. roseus and $M$. luteus have significant antioxidant property showing (IC50 3.5-4.5 mg/mL) through radical scavenging assay of DPPH [9]. This can be obtained from the sources like spinach, banana, cabbage, carrot etc.

\subsection{Anti-inflammatory}

Carotenoids having oxygen in structure like fucoxanthin and astaxanthin has proved to suppress the expression of cytokines IL- 6 , TNF- $\alpha$ and IL- $1 \beta$ and act as pro and antiinflammatory compounds [10]. This can be understood by the figure where it is seen that as carotenoids scavenges the oxygen radicle, it will not further able to interact with NF- $\kappa \mathrm{B}$ which results into macrophage foam cells and decrease in TNF- $\alpha[18,31]$. 


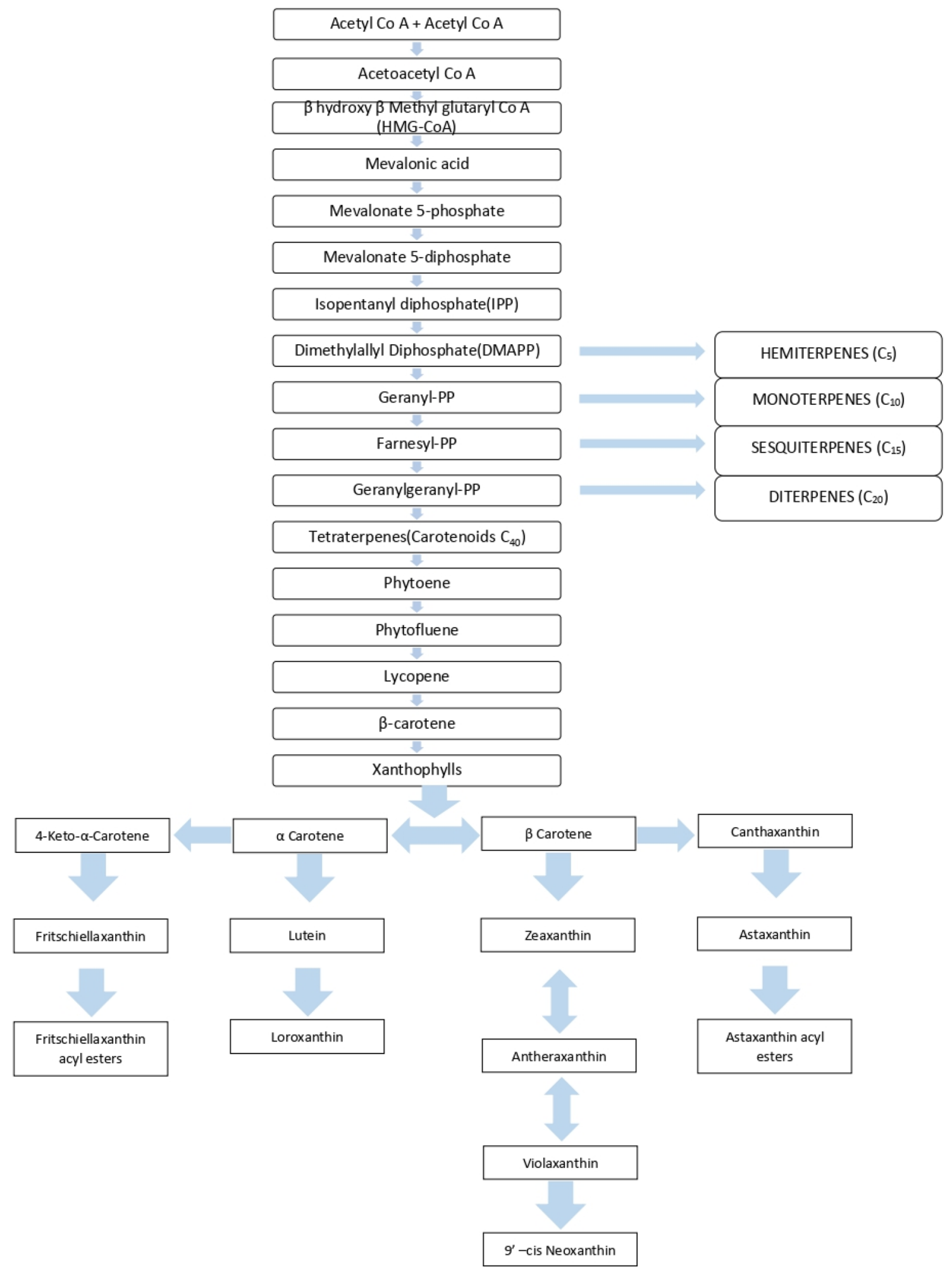

Fig. 1 Biosynthesis pathway of carotenoids [1, 7] 


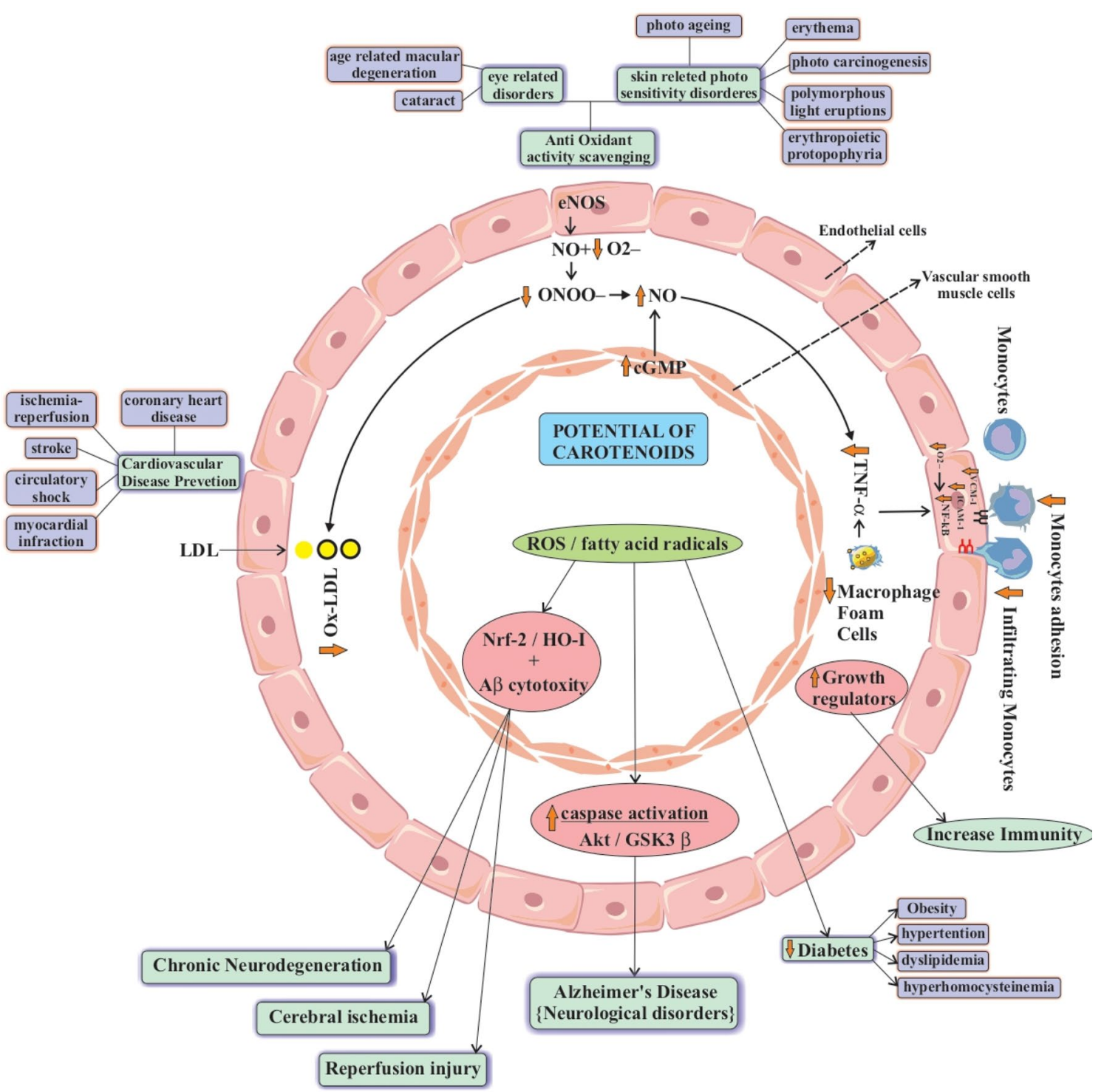

Fig. 2 Potential of carotenoids to prevent diseases [18, 31]

\subsection{Antibacterial and Anti-viral}

In all over the environment billions of bacteria are present and many of them can able to cause chronic diseases and various kind of infections. Moreover, the natural organic pigments of carotenoids can able to combat against those pathogenic bacteria. The hundreds of research experiments show that antibacterial property. According to that the turbidity observations of minimal bactericidal concentration assay shows the lowest concentration of bacterial colonies on nutrient media before that for comparison and cross checking, the Minimal inhibitory concentration assay carried out, consequently 95 percent similarity observed and that study carried out through halobacterial carotenoids against antibiotic resistant microbes which are Staphylococcus aureus,
Klebsiella pneumoniae, Streptococcus epidermis, Pseudomonas aeruginosa and Streptococcus pneumonia. Results observed were terrifying as some species were not able to grow under the presence of carotenoids [11]. Carotenoids has given rise to a new research on its use as anti-viral agent. Carotenoids have shown that it helps to fight against viruses. In an experiment on Herpes Simplex Virus Type 1(HSV-1) it was found that $D$. salina extract and $H$. pluvialis extract can reduce its activity ranging from 50 to $85 \%$ [12].

\subsection{Anticancer}

Several experiments show the potential of carotenoids as anti-cancer agents. It is seen in most of cases that carotenoids arrest the cell cycle which is associated with down 
regulation of cyclin D1, cyclin D2, CDK4 and CDK6 expression. Consequently, it also up regulates GADD45 $\alpha$, which inhibits the entry of cell into S phase [13]. Moreover, compounds like crocin and crocetin extracted from saffron showed the anti-metastasis properties like anti-migration, antiinvasive and anti non adhesive effects in combination on 4T1 cell line in breast cancer [14]. Carotenoids like $\beta$-cryptoxanthin and lycopene are found suppressing the $\mathrm{NF}-\kappa \mathrm{B}$ signalling pathway which is effective against lung cancer and prostate cancer [15]. $\beta$-carotene has found to have anti angiogenic activity that is it helps to halt the process of developing new blood vessels which is often seen in cancerous tumours [16].

\subsection{Cardiovascular Diseases (CVD)}

The various experiments which are occurring inside of body and at lab facility have appeared that carotenoids diminish inflammation and oxidative stress by promoting normal mechanism of cell. In addition to its Many scientific studies also show that by increasing carotenoid rich food helps in reducing CVD in patients $[17,18]$ Carotenoids works straightforwardly by evacuating superoxide anion $\left(\mathrm{O}^{2-}\right)$, in receptive oxygen species (ROS) generation, also have appeared to re-establish nitric oxide (NO) endothelial bioavailability. Consequently, they might be viewed as a potential source of oxidant modulators of endothelial reaction to pro-oxidant/inflammatory stimuli [18]. Certain carotenoids like astaxanthin, lutein and $\beta$ cryptoxanthin are found more involved in preventing cardiovascular disease by oxidizing LDL and decreasing HDL. This can be used in treating myocardial injury and many more [19]. To prove other sources than plants, a carotenoid rich fraction of $D$. salina was taken and tested. Which proved that carotenoids can attenuate the cardiac dysfunction in obese rats [20]. Hence, it can be used as food additives to reduce the obesity associated cardiac dysfunction. Moreover, several critical studies from human are disputed and challenging. According to it especially in vivo experimental procedures for cardiovascular protection are not well known more work to be done is left [18].

\subsection{Ophthalmic Infections}

Vitamin A plays a vital role in human's eye as it is component of rhodopsin which facilitates the efficient transfer of energy from photos of light to electrochemical signals. Deficiency of the vitamin causes night blindness; this can be prevented by up taking carotenoids in appropriate amount leading to good vision [21]. As mentioned earlier only few carotenoids about $10 \%$ can further categorized as pro vitamin A and later in vitamin A [17]. Lutein and zeaxanthin are oxygenated carotenoids present in the macular region of retina responsible for sharp and detailed vision which also serves as filters for blue light from screens and scavenges the free radicle oxygen from retina [6, 22]. Moreover, they can also help to prevent cataract in eyes and with ageing macular degeneration can also be prevented [21].

According to the investigated value of MIC and MBC of carotenoids from Halomonas sp. (HQ 438,316) against antibiotic resistant and ophthalmic bacterial pathogens, there are several bacteria found which causes eye infections and might be cured by carotenoids [11]. In addition to it Staphylococcus aureus can infect cornea (keratitis) or the inner chambers of the eye (endophthalmitis) [23], Escherichia coli in Conjunctivitis [24], and Streptococcus pyogenes and Pseudomonas aeruginosa in blepharitis [24].

\subsection{Neurodegenerative Diseases}

In nervous system increase of oxidative stress results into several neurodegenerative diseases such as Alzheimer's, Huntington's, Parkinson's and amyotrophic lateral sclerosis (ALS). Several diseases are due to $\mathrm{Ca}^{2+}$ inability to signal the molecules but carotenoids like astaxanthin, $\beta$ carotene and lycopene are involved in $\mathrm{Ca}^{2+}$ ion transportation in brain,with proper dietary of carotenoids malfunction due to improper signalling can be reduced [25]. The ability to cross the blood brain barrier, and cell mitochondrial membrane with stability along with antioxidant property carotenoidastaxanthin can be able to reduce the risk of diseases related to the nervous system (neurodegenerative). In addition to its Astaxanthin can combat neurodegenerative diseases by different properties such as anti-apoptosis, reduction in cerebral infarction in brain tissue, lowers ischemia by induced apoptosis, reduction of glutamate release and reduce free radical damage [25, 26]. Also it has been seen that lycopene makes blood brain barrier permeable, and it reduces when certain diseases occur [7]. In Alzheimer's disease, ROS enhances caspase activation along with AKt/GSK-3 $\beta$ signalling. Carotenoids helps to bring this signalling normal and decreases caspase activation. ROS decreasing Nrf2/HO-1 or HO- 1 with $\mathrm{A} \beta$ cytotoxicity results in cerebral ischemia or reperfusion injury and chronic neurodegeneration [8].

\subsection{Anti-hyperglycaemia}

As indicated by the statistical analysis and of assessment of European Prospective Investigation into Cancer and Nutrition-Netherlands, from human utilization of carotenoids in their regimen can decrease the risk of type 2 diabetes. Notwithstanding it after the conclusive change of incorporated a few parameters like age, sexual orientation, risk factors, and diet, expressed that for beta carotene Hazard proportion found as 0.78 though for alpha-carotene, 0.85 . Additionally, that studies demonstrate that usage of carotenoids can diminish the risk of diabetes type 2 for sound women and 
men [27]. Main reason of hyperglycaemia is the lifestyle and food habits. Due to hypertension oxidative stress is induced which results in complexity with body by associating it with obesity, diabetes, dyslipidaemia and hyperhomocysteinemia. Here, fatty acid radicles and reactive oxygen species play vital role in increasing the GR, GPx and other hormones in body leading to diseases. Carotenoids by scavenging this fatty acid radicle and ROS brings regulatory signals back to normal and reduce (40 to $79 \%$ ) diseases $[28,29]$.

\subsection{UV Radiation Protection}

Not only limited to anti-oxidant and anti-inflammatory, UV light protection can be also determined through various studies which in the stated experiment of Efficacy of UV-C protective activity of carotenoid pigments isolated from $M$. roseus and $M$. luteus on growth of $\mathrm{S}$. faecalis proved that the 21 colonies out of 31 colonies has been shown stable and strong resistant against UV exposure with approximately 70 to 95 percentage of coefficient of variation at $120 \mathrm{~min}$ [9]. In various carotenoids Beta-carotene and canthaxanthin have explicit photo defensive properties. In an experiment it indicated that reactive oxygen species and other reactive free radicals helps alongside in oxygen quenching, which respond in blood and skin erythropoietic protoporphyria patients. Moreover, erythropoietic protoporphyria patients have shown decreased level of $\beta$ carotene in their serum for which they need to take it as dietary supplement [23, $30,31]$ Moreover, it is also notices that lycopene and beta carotene helps to reduce skin redness and damage under UV rays [6] which can be helpful as soothing agent under UV rays of sun.

\subsection{Proliferating Agent}

Major role of carotenoids differentiated into pro vitamin A is in cell differentiation and tissue growth [21]. Immunomodulating function has been observed while experimenting on spleen cells showing increased response to mitogens, from this it may be derived that carotenoids enhance the activity of natural killer cells [32]. Also it helps to boost immune system by rising cell to cell communication by increasing the exchange of growth regulatory signals this leads to apoptosis in damaged cells [6].

\subsection{Anti-tuberculosis}

Nowadays world is fighting against Multidrug resistant (MDR) bacteria i.e. Mycobacterium tuberculosis. With a series of experiments on biomass of $C$. vulgaris, this come up with the new therapeutic application of carotenoids as anti-Tuberculosis agent. $100 \%$ of inhibition was observed at $100 \mu \mathrm{g} / \mathrm{mL}$ by fatty acids-carotenoids complexes (sample 1 red oil) and $50 \mu \mathrm{g} / \mathrm{mL}$ of (sample 2 brown oil) [33]. Much work is still needed in this field as this disease is related to oxygen and carotenoids are known for its antioxidant properties.

\subsection{Regenerative Liver}

Consumption of fruits and vegetables and several biological reactions states different valuable properties along with antioxidant in regeneration (cure) of liver. Carotenoids are utilised in liver and lipoprotein component within the purpose of secretion into blood circulatory system. The utilised pigments of carotenoids combat oxidation mechanism during high level of free radical species in liver organ also these features prevent the growth of liver dysfunctionality [34-36]. Moreover several studies stated that b-carotene, lycopene, lutein, and b-cryptoxanthin types of carotenoids have antioxidant effects against lipid peroxidation in rat liver $[35,36]$. Carotenoids are found connected with adipose tissue and multiple serum in humans for different metabolism such as insulin sensitivity in liver and adipose tissue [37]. In Most of the cases liver damage happens from the high value of cholesterol. A marine Astaxanthin (Carotenoid) can able to function as protection for cells, fats and other membrane proteins towards oxidative damage. Moreover, the intestinal cells partially allow Astaxanthin enter into chylomicrons. The Astaxanthin dissolved in chylomicrons through lipid enzymes are secreted from lymph to liver. In chylomicrons ROS will be quickly evacuated from different tissues as well as from liver. In that way amongst all carotenoids, Astaxanthin is one that can have ability to fight and cure liver [26].

\subsection{As Nutrient}

Intake of higher total carotenoids has shown the benefit of reduction in fracture incidence by increasing bone density and has provided positive effect of bone mineral status at all age group which resulted in reduction of under carboxylated osteocalcin, hence regular intake of carotenoid rich foods may help in decreasing the osteoporosis in patients [38]. Norbixin an apocarotenoids, has found to have antioxidant and food additive application also helps in repairing ROS dependent DNA damage. Lycopene is used as food colouring agent and flavour modifier found from the natural source tomato [16] used commercially in making sauce, ketchup and as intensifier in food, pharmaceutical and dye industries [5].

\section{Conclusion}

From the above discussion it can be said that this mighty molecules of nature has immense power to defeat many diseases as it not only prevents illness but also helps to cure 
them in certain cases. This carotenoids can be microencapsulated and can be commercialized as an antioxidant product, nutraceutical and pharmaceutical [16]. As world has come across to this hidden truth its demand have increased due to its properties of healing tissues and as a food additives (natural colourant) with nutritional value [5]. But much less is still know yet a far journey of research has to be taken to know carotenoid's potential and power.

Acknowledgements There is no technical and financial support given.

\section{Compliance with Ethical Standards}

Conflict of interest The authors declares no conflict of interest.

Open Access This article is licensed under a Creative Commons Attribution 4.0 International License, which permits use, sharing, adaptation, distribution and reproduction in any medium or format, as long as you give appropriate credit to the original author(s) and the source, provide a link to the Creative Commons licence, and indicate if changes were made. The images or other third party material in this article are included in the article's Creative Commons licence, unless indicated otherwise in a credit line to the material. If material is not included in the article's Creative Commons licence and your intended use is not permitted by statutory regulation or exceeds the permitted use, you will need to obtain permission directly from the copyright holder. To view a copy of this licence, visit http://creativecommons.org/licenses/by/4.0/.

\section{References}

1. Martin L., Chapter 21-Carotenoids, in The Chlamydomonas Sourcebook (Second Edition) vol 2 (Academic Press, New York, 2009) pp. 799-817.

2. P.M. Bramley, 11-lsoprenoid Metabolism, Plant Biochemistry (Academic Press, New York, 1997), pp. 417-437

3. Pither RJ, Canning-Quality changes during canning, in Encyclopedia of Food sciences and Nutrition, Second Edition (2003), p. 845-851.

4. M.K. Dhar, S. Mishra, A. Bhat, S. Chib, S. Kaul, Plant carotenoid cleavage oxygenases: structure-function relationships and role in development and metabolism. Brief. Funct. Genom. 19(1), 1-9 (2019). https://doi.org/10.1093/bfgp/elz037

5. N. Mezzomo, S.R. Ferreira, Carotenoids functionality, sources, and processing by supercritical technology: a review. J. Chem. (2016). https://doi.org/10.1155/2016/3164312

6. S.B. Astley, ANTIOXIDANTSI role of antioxidant nutrients, in Defense Systems, Encyclopedia of Food Sciences and Nutrition, 2nd edn (Academic Press, New York, 2003), p. 282289

7. Merhan $\mathrm{O}$, in The Biochemistry and Antioxidant Properties of Carotenoids, Carotenoids, ed. by D.J. Cvetkovic, G.S. Nikolic (IntechOpen, Londra, 2017)

8. E. Aziz, R. Batool, W. Akhtar, S. Rehman, T. Shahzad, A. Malik et al., Xanthophyll: health benefits and therapeutic insights. Life Sci. 240, 117104 (2020)

9. D. Mohana, S. Thippeswamy, R. Abhishe, Antioxidant, antibacterial, and ultraviolet-protective properties of carotenoids isolated from Micrococcus spp. Radiat. Protect. Environ. 36(4), 168-174 (2013)
10. I. Jaswir, H.A. Monsur, Anti-inflammatory compounds of macro algae origin: a review. J. Med. Plants Res. Acad. J. 5(33), 71467154 (2011)

11. S. Ravikumar, G. Uma, R. Gokulakrishnan, Antibacterial property of halobacterial carotenoids against human bacterial pathogens. J. Sci. Ind. Res. 75(4), 253-257 (2016)

12. S. Santoyo, L. Jaime, M. Plaza et al., Antiviral compounds obtained from microalgae commonly used as carotenoid sources. J. Appl. Phycol. 24, 731-741 (2012)

13. T.P. Almeida, A.A. Ramos, J. Ferreira, A. Azqueta, E. Rocha, Bioactive compounds from seaweed with anti-leukemic activity: a mini-review on carotenoids and phlorotannins. Mini-Rev. Med. Chem. 20, 39-53 (2020)

14. L. Arzi, R. Hoshyar, N. Jafarzadeh et al., Anti-metastatic properties of a potent herbal combination in cell and mice models of triple negative breast cancer. Life Sci. (2020). https://doi. org/10.1016/j.lfs.2019.117245

15. J.Y. Lim, X.-D. Wang, Mechanistic understanding of $\beta$-cryptoxanthin and lycopene in cancer prevention in animal models. BBA Mol. Cell Biol. Lipids (2020). https://doi. org/10.1016/j.bbalip.2020.158652

16. R.G. Bodade, A.G. Bodade, Chapter 17- Microencapsulation of bioactive compounds and enzymes for therapeutic applications, in Biopolymer-Based Formulations (Elsevier, Amsterdam, 2020) p. 381-404

17. D.S.P. Abdalla, CORONARY HEART DISEASEl Antioxidant Status, in Encyclopedia of Food Sciences and Nutrition, 2nd edn (Academic Press, New York, 2003), p. 1654-1663

18. N. Di Pietro, P. Di Tomo, A. Pandolfi, Carotenoids in cardiovascular disease prevention. JSM Atheroscler. 1(1), 1002 (2016)

19. F.J. Pashkow, D.G. Watumull, C.L. Campbell, Astaxanthin: a novel potential treatment for oxidative stress and inflammation in cardiovascular disease. Am. J. Cardiol. 101, 58D-68D (2008)

20. F.K. El-Baza, H.F. Alyb, H.I. Abd-Allac, The ameliorating effect of carotenoid rich fraction extracted from Dunaliella salina microalga against inflammation-associated cardiac dysfunction in obese rats. Toxicol. Rep. 7, 118-124 (2020)

21. R.B. Rucker, J. Morris, A. Fascetti Chapter 23-vitamins, in Clinical biochemistry of domestic animals, 6th edn (Academic Press, New York, 2008), p. 695-730

22. T.T. Berendschot, J. Plat, Chapter 44-Plant stanol and sterol esters and macular pigment optical density, in Handbook of Nutrition, Diet and the Eye (Academic Press, New York, 2014), p. 441-449

23. R.J. O'Callaghan, The pathogenesis of staphylococcus aureus eye infections. Pathogens 7(1), 9 (2018). https://doi.org/10.3390/patho gens 7010009

24. M. Teweldemedhin, H. Gebreyesus, A.H. Atsbaha, S.W. Asgedom, M. Saravanan, Bacterial profile of ocular infections: a systematic review. BMC Ophthalmol. 17(1), 212 (2017). https://doi. org/10.1186/s12886-017-0612-2

25. J. Rzajew, T. Radzik, E. Rebas, Calcium-involved action of phytochemicals: carotenoids and monoterpenes in the brain. Int. J. Mol. Sci. 21, 1428 (2020)

26. K. Kowsalya, N. Vidya, V. Vijayalakshmi, M. Arun, Super nutritive marine astaxanthin, an effectual dietary carotenoid for neurodegenerative diseases. Int. Res. J. Multidiscipl. Tech. Maple Tree J. 1(6), 115-124 (2019)

27. I. Sluijs et al., Dietary intake of carotenoids and risk of type 2 diabetes. Nutr. Metabol. Cardiovasc. Dis. (2015). https://doi. org/10.1016/j.numecd.2014.12.008

28. T.C. do Nascimento, C.B.B. Cazarin, M.R. Maróstica Jr, A.Z. Mercadante, E. Jacob-Lopes, L.Q. Zepka, Microalgae carotenoids intake: influence on cholesterol levels, lipid peroxidation and antioxidant enzymes. Food Res. Int. 128, 108770 (2020) 
29. F. Shidfar, G.N. Arjomand, Chapter 24-Glucose intake and utilization, in Pre-Diabetes and Diabetes: Tomato and Diabetes, Glucose Intake and Utilization in Pre-diabetes and Diabetes (Academic Press, New York, 2015), p. 301-313.

30. J. von Laar, W. Stahl, K. Bolsen, G. Goerz, H. Sies, $\beta$-Carotene serum levels in patients with erythropoietic protoporphyria on treatment with the synthetic all-trans isomer or a natural isomermixture of $\beta$-carotene. J. Photochem. Photobiol. B 33, 157-162 (1996)

31. J. Fiedor, K. Burda, Potential role of carotenoids as antioxidants in human health and disease. Nutrients 6, 466-488 (2014)

32. H. Jyonouchi, R.J. Hill, Y. Tomita, R.A. Good, Studies of immunomodulating actions of carotenoids. I. Effects of $\beta$-carotene and astaxanthin on murine lymphocyte functions and cell surface marker expression in vitro culture system. Nutr. Cancer 16(2), 93-105 (1991). https://doi.org/10.1080/01635589109514148

33. T.S. Kumar, A. Josephine, T. Sreelatha, V.A. Dusthackeer, B. Mahizhaveni, G. Dharani et al., Fatty acids-carotenoid complex: an effective anti-TB agent from the chlorella growth factorextracted spent biomass of Chlorella vulgaris. J. Ethnopharmacol. 249, 112392 (2020)
34. M. Sugiura, Chapter 27-Carotenoids: liver diseases prevention, in Bioactive Foods as Dietary Interventions for Liver and Gastrointestinal Disease (Academic Press, New York, 2013), p. 421-436

35. H. Chen, A. Tappel, Protection by multiple antioxidants against lipid peroxidation in rat liver homogenate. Lipids 31, 47-50 (1996)

36. P. Whittaker, W.G. Wamer, R.F. Chanderbhan, V.C. Dunkel, Effects of alpha-tocopherol and beta-carotene on hepatic lipid peroxidation and blood lipids in rats with dietary iron overload. Nutr. Cancer 25, 119-128 (1996)

37. A. Harari, A.C.F. Coster, A. Jenkins, A. Xu, J.R. Greenfield, D. Harats, A. Shaish, D. Samocha-Bonet, Obesity and insulin resistance are inversely associated with serum and adipose tissue carotenoid concentrations in adults. J Nutr 150(1), 38-46 (2020). https ://doi.org/10.1093/jn/nxz184

38. W. Jeri, Nieves, Chapter 74-Alternative Therapy through Nutrients and Nutraceuticals (Academic Press, New York, Osteoporosis fourth edition, 2013), pp. 1739-1749 